\title{
Corporate Governance, Sustainable Development and Value Creation—Some Evidences From Italian Listed Companies
}

\begin{abstract}
Alex Almici
Brescia University, Brescia, Italy

Modern corporate situations, characterized by the globalisation of the markets and of the information, highlight the need to link the potential of a not transient growth to the adequate reconciliation of all the expectations converging around the entrepreneurial formula and not only of those attributable to shareholders. In such a defined context, corporate governance tends to evolve from a situation of primary care for the expectations of shareholders (shareholder's view) and for the correlated financial responsibility, to a wide consideration of all the stakeholders (stakeholder's view) and related responsibilities (financial, environmental, social, administrative). The correct carrying out of governance processes requires, therefore, a clear focus on sustainable development and on the related assumption of a concept of global responsibility. The decisions made by the governing bodies must be driven by the purpose to create value in the long term according to conditions of fairness and sustainable development. To sum up, this research aims to deepen the existing connections between corporate governance, sustainable development and value creation on the basis of the empirical analysis of a limited number of listed Italian companies afferent to the public utilities sector. The paper, based on a deductive approach, is composed of two distinct but strictly connected parts: the first theoretical and the second empirical. The empirical research consists of a content analysis of the most recent documents (sustainability reports and annual reports) worked out by the selected companies. The results obtained about the degree respect of sustainable development conditions by each company are linked to the related value dimension (social, economic, competitive and environmental performance) aimed at verifying if the assumption of a corporate governance approach inspired by sustainability is susceptible of favouring the company development in a medium long term. From the delivered research it emerges how public utilities that promote behaviours in line with the sustainability conditions are marked out by stable growth paths. Conversely, the companies that assume a vision mainly addressed to the economic dimension, neglecting the other areas are generally compromised in the performance realized.
\end{abstract}

Keywords: corporate governance, sustainable development, shareholder’s view, global corporate responsibility

\section{Corporate Governance and Global Corporate Responsibility}

In the current scenario, characterized by strong competitiveness and by an easy possibility of comparison of corporate performances, the safeguard of all interests that merge in the company, and not only a part of them, as it used to happen in the past, proves to be an essential condition for sustainable development (Jacobs, 1977). In

Alex Almici, Ph.D. in Business Administration, Department of Business Administration, Brescia University.

Correspondence concerning this article should be addressed to Alex Almici, Università degli Studi di Brescia, Contrada S. Chiara, Brescia 25122, Italy. E-mail: alex.almici@eco.unibs.it. 
other words, without neglecting the importance assigned to the expectations of shareholders, the need to revaluate all social actors is stated according to the criteria of tight integration between economic expectations (adequate remuneration of the capital) and socio-environmental expectations (professional growth, environmental health and satisfying social relationships, etc.) (Freeman, 1984).

Companies awareness statement about the importance of the protection of all corporate interlocutors leads to a review of corporate governance systems in order to avoid the reiteration of iniquitous practices aimed at: satisfying the expectations of only few stakeholders (especially shareholders); safeguarding, within the shareholders, the interests of only the majority ones. In particular, corporate governance tends to evolve from a situation of primary attention to the expectations of shareholders (shareholder's view) and of the respective economic responsibility, to an ample consideration of all social actors (stakeholder's view) towards whom the company assumes complex responsibility (environmental, social, administrative) (Salvioni, 2009). As a matter of fact, since non-ephemeral corporate growth implies the protection of all interests merged in the company, the effective execution of corporate governance activity requires a fair balancing of cost effectiveness evaluation and, at the same time, of socio-environmental sustainability evaluation. The multidimensionality of the expectations that merge in the company actually underlines the importance of carrying out a behaviour based on the contextual respect of business, law, ethic and ecosystem conditions. It follows that decisions of corporate governance have to be taken according to an orientation to global responsibility centered on balancing: economic responsibility (referable to the protection of all social interlocutors, bearers of economic interest), social responsibility (towards all those who interact with the company in various ways), environmental responsibility (referable to the respect of the ecosystem), legal/administrative responsibility (referable to the observance of civil and fiscal laws).

In the last years, the emphasis on economic-financial short term objectives has been substituted by the assumption of a long term multidimensional vision, centered on the fair balancing of economic growth, social development and environmental safeguard. The decisions of corporate governance bodies have therefore to be inspired by the intention to create a long term value according to the conditions of equity and sustainable development (Fukuyama, 1995; Carroll, 1993). This last one is, at the same time, an orientation factor for corporate governance activity and a guarantee element for the optimization of the performances in the interest of all effective and potential corporate interlocutors.

The correct execution of corporate governance processes requires, therefore, a clear focus on sustainable development and on the related assumption of the global responsibility concept, founded on the observance of the laws and ethical principles, on the respect of the ecosystem and on the creation of widespread trust relations (Waddock \& Graves, 1999; Welford, 2000; Paine, 2003). As a matter of fact, only corporate governance decisions inspired by the balancing of all relevant dimensions (economic, social, administrative, and environmental) are proved to be able to minimize the corporate risk and to guarantee the effective pursuit of the company mission.

Corporate governance is a management level activity aimed at the correct composition of all important expectations, according to a global view of the responsibilities that the company takes in the course of time. More precisely, corporate governance is associated to the execution of administrative, control and communication functions by specific bodies (board of directors, sole director, managing bodies, etc.).

Corporate governance bodies receive their mandate from the property to provide for: on the one hand, the improvement of choices and orientation of the management (administrative function); on the other hand, the 
correction and effectiveness check of corporate behaviours (control function), as well as addressing all important information for the appropriate qualification of the company in the environment (communication function). In this sense, corporate governance presents itself as a complex activity, characterized by the importance assigned to the promotion of success behaviours, regardless of the size, the corporate designation, the ownership structure and the funding system of the companies.

As it has already been explained, the opportunity of a non-ephemeral value growth can only be created in the presence of conditions of real satisfaction of all stakeholders. However, this value has to be produced according to the criteria of sustainability, equity and ethic; it has to be aimed at the maintenance of the corporate development, directly, through reinvestment and indirectly through the fair sharing among stakeholders.

\section{Sustainable Development and Corporate Value}

The creation of a value is synthetically identifiable in the contextual optimization of economic, competitive, social and environmental company performances respectful of laws and ethical principles. In other words, the success of a company requires that the company's choices are taken with the intention to meet all stakeholders' expectations according to high sustainability parameters.

In the above mentioned area, the notion of "sustainable development" takes main importance; this expression was officially introduced in the economics and politics international language by the so-called Brundtland Report, elaborated and published by the World Commission on Environment and Development (1987), a commission presided by the Norwegian Prime Minister Gro Hurlen Brundtland.

The document under discussion defines as sustainable "the development that satisfies the needs of the present world without compromising the ability of the future generations to satisfy themselves their needs". In particular, the "sustainable development" sets up an essential condition for the growth of the company in medium-long term and implies the tight integration of all relevant company dimensions (triple bottom line) (Elkington, 1997) according to the adoption of an approach to global responsibility. More precisely, the attainment of company success requires the contextual realization of sustainability conditions of the following types:

- Environmental, in terms of utilization of natural resources in respect of the limitations imposed by the capability of regeneration and absorption by the ecosystem;

- Economic, in as much as the enterprise optimizes the revenue and competitive performances, yet without producing a negative impact on the economic development of the territory in which it is inserted;

- Social, with regard to the contribution offered by the enterprise for the development of the society, with particular care to the improvement of life and work conditions of the citizens.

The previous considerations highlight how the respect of the conditions of company sustainability has to inform all decisions taken by the corporate governance bodies that, as we've already observed, are asked to acknowledge the expectations of the stakeholders and to translate them in precise directions destined to address the management behaviours towards the attainment of the results. The adequate satisfaction of the expectations of all social actors, according to the conditions of sustainable development, therefore, sets up an important factor for value creation in the mid-long term. In particular, with the time the company's growth is confirmed by the appreciation of specific success conditions, precisely revenue, capital, monetary and financial balance (economic success); confluence of approvals by the different company interlocutors about the company 
planning proposal (social success); execution of the economic combinations in respect of the ecosystem (environmental success); prevailing position in the economic market we refer to (competitive success).

At the beginning of this century the awareness has spread that the non-ephemeral value creation doesn't exhaust with the achievement of satisfactory economic results, but that it implies the contextual presence of further conditions, synthetically referable to the achievement of the necessary internal and external consent, to the environmental safeguard and to the prevailing position within its competitive arena.

The lasting effectiveness potential of an enterprise is therefore mainly referable to a multiplicity of variables that have their primary confirmation in the ability to positively address the internal and external behaviours. These last ones should be therefore directed towards the optimization of the conditions of economic and non-economic balance, in order to meet precise expectations, within the correct use of the limited resources available.

\section{The Empiric Research: Purpose, Selection of the Companies and Methodology}

The empiric research, whose results are illustrated later on, is aimed at verifying, specifically, the relations existing among corporate governance, sustainable development and value creation. More precisely, it is aimed at verifying if companies that have corporate governance systems that promoted the assumption of global responsibility and of an orientation to sustainable development have actually distinguished themselves for the value they created.

In order to achieve this purpose, the attention has concentrated on Italian companies afferent to the public utilities sector listed by the January 31, 2011 (17 companies in total ${ }^{1}$ ). The choice of focusing the analysis on the so-called "public utilities" depends on different motivations among which it is appropriate to report:

- Companies definable as "public utilities" generally carry out their economic combinations mainly using the resources that are offered by the ecosystem according to an endowment susceptible of exhaustion in the course of the years; here in particular, the necessity to evaluate if the execution of the company activity occurs in conformity with the conditions of sustainable development stands out;

- In the last years many companies working in the public utilities services have been privatized and listed, with a consequent increase of the stakeholders involved and emphasis on the necessity to adopt a multidimensional corporate governance approach.

Regarding the above mentioned companies, the analysis was conducted on the basis of the information spread through the sustainability report worked out in 2007, 2008, 2009; at the moment of the research, the 2010 report wasn't considered because it hadn't been made available yet. In particular the level of orientation towards sustainable development of every company was esteemed with regard to: the choice to arrange the sustainability report by corporate governance bodies; the quality profile of the forwarded information; the content of the specific sustainability report. In order to evaluate the quality and content aspects, the combination of guidelines worked out by the Global Reporting Initiative ${ }^{2}$ (GRI) was adopted as a reference.

\footnotetext{
${ }^{1}$ The following companies were considered: A2A, Acea, Aceagas-Apa, Acque Potabili, Acsm-Agam, Alerion-Cleanpower, Ascopiave, Edison, Edison Rsp, Enel, Enel Green Power, Erg Renew, Ergycapital, Falk Renewables, Hera, Iren, K. R. Energy.

2 The Global Reporting Initiative is an independent institution whose task is to develop and spread the guidelines for globally applicable sustainability reports. This institution was founded in 1997 on the initiative of the American government body Coalition for Environmental Responsible Economies (CERES) in partnership with the United Nations Environment Program (UNEP). At the moment, the Global Reporting Initiative avails itself of the cooperation of various international organization and research centers, as well as of the participation of several multinationals.
} 
The results obtained about the degree respect of sustainable development conditions by each company were later on linked to the related value dimension (economic, competitive, social and environmental performance) aimed at verifying if, in reality, the assumption of a corporate governance approach inspired by sustainability is susceptible of favouring the company development in medium-long term.

In particular, since the corporate value has been identified, as already observed, in the contextual optimization of company performances (economic and non-economic), the value dimension of each company was outlined on the basis of the following indicators: average proceeds of sales (2007-2009) as competitive success indicator. The reference threshold adopted with regard to this is $€ 1,000,000,000.00$;

- Average ebitda ${ }^{3}$ (2007-2009) as an economic success indicator, whose attainment is considered as verified with values above $€ 200,000,000.00$. In order to measure the parameter on approval and the one above mentioned, the consolidated balance sheet has been taken into consideration or if that was missing, the balance sheet;

- Inclusion in the basket for the elaboration of the ethic index FTSE4GOOD Europe ${ }^{4}$, in order to evaluate the social and environmental success. In particular, this parameter represents a share index afferent to the index category FTSE4GOOD ${ }^{5}$, susceptible of including in its basket only those shares of companies satisfying specific conditions regarding: environmental sustainability; the attention to social requests; the relations with the stakeholders.

\section{Noticed Results}

The research under discussion aims first at verifying the number of companies, among the selected ones, that the sustainability report arranges. With regard to this, few are the companies working in the public utilities sector that draw up this document: only six out of seventeen (35\%) work on their sustainability report, two companies, instead, refer to the report prepared by their parent company.

With reference to the drawing up time of the sustainability report as regards the initial listing the trend to arrange the report under discussion in the medium term immediately after the listing is noticed. Such evidence can be explained by the fact that implies that the admission to the Stock Exchange on the one hand leads into the progressive increase of the expectations that merge in the company; on the other hand, it emphasizes the correlated necessity to satisfy all the stakeholders according to sustainability conditions (see Table 1).

In order to verify the quality of the activated communication, the following aspects were appraised:

(1) Model used as a reference. With regard to this, the adoption of the model of Group Reporting Initiative was considered, in order to carry out this analysis, as a factor of qualification of the information provided, considered the great importance assumed in national and international circles by the related Guidelines ${ }^{6}$ (Simerly, 1999);

\footnotetext{
${ }^{3}$ Earnings before interest, taxes, depreciation and armotization.

${ }^{4}$ With regard to this, it has to be underlined that the choice of the index under discussion happened with the awareness of the presence of other ethical indexes of similar significance.

5 The indexes FTSE4Good are issued by the English society FTSE, shared by the London Stock Exchange and by the Financial Times. In particular, the indexes afferent to the group FTSE4Good are eight in total: Four are benchmarks (FTSE4Good Uk 50 Index, FTSE4Good Europe 50 Index, FTSE4Good Global 100 Index, FTSEGood US 100 Index), or object of potential negotiations. The choice and definition of ethical screening criterions are committed to an independent Advisory Committee while the information and data about the enterprises object of evaluation are supplied by a British research Institution (EIRIS, Ethical Investment Research Services).

${ }^{6}$ The last version of GRI Guidelines dates back to 2006 and it is the third edition (G3).
} 
Table 1

First Sustainability Report and Italian Stock Exchange Listing

\begin{tabular}{lll}
\hline Public utilities that draw up the sustainability report & Listing & First sustainability report \\
\hline A2A ${ }^{*}$ & 2008 & 2008 \\
ACEA & 1999 & 2002 \\
EDISON & 2002 & 2004 \\
ENEL & 1999 & 2002 \\
HERA & 2003 & 2003 \\
IREN ${ }^{* *}$-IRIDE & 2000 & 2006 \\
\hline
\end{tabular}

Notes. ${ }^{*}$ A2A Spa society was founded on January 1, 2008, as a consequence of the incorporation of ASM Spa in AEM Spa. ${ }^{* * *}$ Iren Spa society was founded on July 1, 2010, after the merger of Enia Spa in Iride Spa. With regard to the considered years (2007-2009), the analysis has to be referred to the Iride Spa society.

(2) Conformity degree of the sustainability report compared to what is expected by the framework Gri. With regard to this, both the compliance declaration realized by the company on the basis of the provided codifications $(\mathrm{C}, \mathrm{C}+, \mathrm{B}, \mathrm{B}+, \mathrm{A}, \mathrm{A}+)$ and the eventual presence of a revision report by an external subject were taken into consideration.

With regard to the point sub. (1), all the public utilities that work out the sustainability report chose as main reference the guidelines spread by the Group Reporting Initiative (see Table 2).

Table 2

Model Adopted for Carrying out the Sustainability Report

\begin{tabular}{llll}
\hline Variable & No. of companies, 2007 & No. of companies, 2008 & No. of companies, 2009 \\
\hline Reference to the GRI guidelines & $5^{*}$ & 6 & 6 \\
\hline
\end{tabular}

Note. * With regard to 2007, the number of companies considered is five instead of six because A2A was founded in 2008.

With reference to the declared compliance degree instead, a good quality level of the spread sustainablility report was generally found: in 2007, three companies out of five declare to have reached the maximum level $(\mathrm{A}+)$, while in 2008 the $\mathrm{A}+$ reports are four out of six, according to what every single company declared, and in 2009, five out of six. Only one company doesn't give any indication about the compliance degree reached, even though with exclusive regard to 2008. The former considerations highlight a growing trend of qualitative improvement (see Table 3).

Table 3

Compliance Degree as Regards the GRI Guidelines

\begin{tabular}{llll}
\hline Variable & No. of companies, 2007 & No. of companies, 2008 & No. of companies, 2009 \\
\hline Compliance degree & & & \\
C & & & \\
C + & & 1 \\
B & 2 & 1 & 5 \\
B & & & \\
A & 3 & 4 & \\
A + & & 1 & \\
nd $^{*}$ & &
\end{tabular}

Note. * not declared. 
The declared compliance degree as regards the GRI guidelines is, in the majority of the cases, validated in the account worked out after the revision of the sustainability report by a third person. In this sense, the revision of the document under discussion is executed with regard to four companies out of five in 2007, four out of six in 2008, and five out of six in 2009; in this case too a light improvement in the course of time is noticed.

Considering the economic, environmental and social indicators that the companies under discussion worked out following the guidelines of the Group Reporting Initiative, it is possible to obtain indications about the decisions taken by corporate governance bodies and about the consequent behaviours with regard to the realization of high sustainability conditions.

In order to do so, some of the most important parameters were selected among those provided on the basis of the indications of the Group Reporting Initiative:

(1) The size of the shared value added, the amount of investments aimed at fighting the problem of climatic changes, the expense percentage that can be ascribed to local suppliers as well as the presence of selection processes of the same suppliers on the basis of ethical, commercial, financial and technical reliability. These indicators figure out identification marks according to the degree of effective assumption of the economic responsibilities;

(2) The volume of raw materials used, the consumption of direct energy, the total water collecting per source, the size of greenhouse effect gas emission in the environment, the total weight of waste material produced. These parameters refer to the environmental dimension and offer indications about the respect degree of the ecosystem in relation with the execution of the business activity;

(3) The staff turnover rate, the accidents on working place frequency, the average training hour per employee, the number of discriminating practices episodes, possible sanctions received.

Only those companies that meet at the same time all the above mentioned indicators are considered to have corporate governance systems that, in reality, addresses the company activities according to economic, social and environmental sustainability criterions.

\section{Economic Responsibility}

With reference to the above mentioned economic indicators, the percentage of distribution of the value added produced highlights the inclination of the company to meet the expectations of all corporate stakeholders. With regard to this, $60 \%$ was set as the minimum limit, so that the destination measure of the richness created for the social actors can be considered in line with the conditions of sustainable development. With regard to this, it was proved that all six companies involved assigned more than $60 \%$ of the value added produced in those considered years (see Table 4).

Table 4

Distribution of the Value Added to the Stakeholders Above 60\%

\begin{tabular}{llll}
\hline Variable & No. of companies, 2007 & No. of companies, 2008 & No. of companies, 2009 \\
\hline Value added distributed & 5 & 6 & 6 \\
\hline
\end{tabular}

The appraisal of the amount of these pragmatic investments for the management of the climatic changes enables to measure the financial effort spent on the safeguard of the ecosystem, generally resorting to the strengthening of 
renewable sources; with regard to this, $€ 1,000,000.00$ is the minimum limit adopted. From the sustainability report analysis it emerges that only three companies declare the execution of investments above the amount outlined before aimed at fighting the climatic problems for all the years taken into consideration (see Table 5).

Table 5

Investments Above $€ 1,000,000.00$ for the Management of Climatic Changes

\begin{tabular}{llll}
\hline Variable & No. of companies, 2007 & No. of companies, 2008 & No. of companies, 2009 \\
\hline $\begin{array}{l}\text { Total investments for the } \\
\text { management of climatic } \\
\text { changes problem }\end{array}$ & 3 & 3 & 3 \\
\hline
\end{tabular}

Finally, the appraisal of the expense percentage referable to local suppliers, as well as the activation of procedures for their selection, highlights the attention paid to the companies so that their supplying systems base themselves mainly on the use of operators that meet the requirements of ethical, commercial, financial and technical reliability. The recourse to suppliers afferent to the same territorial circles of the supplied company simplifies the effectiveness of these controls as well as the possibility that the outcome of the checks results as positive, ensuring the acquisition of the necessary resources in respect of the equity, ethical and environmental safeguard conditions. With regard to this, $70 \%$ is the minimum percentage of expense from local suppliers, so that a supplying can be delivered according to sustainability conditions. The gathered data highlight that only three companies hit this limit in all the considered years; it was noticed however that all the companies taken into consideration select their suppliers (see Table 6).

Table 6

Expenses Percentage Above 70\% Referable to Local Suppliers

\begin{tabular}{llll}
\hline Variable & No. of companies, 2007 & No. of companies, 2008 & No. of companies, 2009 \\
\hline Expense percentage from local suppliers & 3 & 3 & 3 \\
\hline
\end{tabular}

\section{Environmental Responsibility}

The indicators selected in order to appraise the environmental sustainability were observed in the reference years (2007-2009) with the aim of verifying the trend (growing or diminishing); since the parametrs under discussion express the degree of impoverishment imposed to the ecosystem, even if indirectly, a possible increase has to be read as a scarce compliance of sustainability and environmental principles (see Table 7).

Table 7

Environmental Performance Trend in 2007-2009

\begin{tabular}{lll}
\hline Variable & No. of companies-diminishing trend & No. of companies-growing trend \\
\hline Raw materials consumption & 3 & 3 \\
Electric Energy consumption & 3 & 3 \\
Total water collecting & 4 & 2 \\
Green house-effect gas emission & 3 & 3 \\
Total waste weight & 3 & 3 \\
\hline
\end{tabular}

In particular, from the research it came out that:

- The weight of the waste produced, the consumption of raw material and electric energy, the 
greenhouse-effect gas emission show a diminishing trend for only three companies;

- The total water collecting shows a light decrease for four companies.

\section{Social Responsibility}

The indicators later on analyzed aim principally at reporting the satisfaction degree of a specific class of interlocutors, represented by subordinate workers. In particular, observing the staff turnover rate, it is possible to detect the satisfaction degree of the expectations of the subordinates: the bigger is the value indicator, the lower is generally the appeal that connotes the working place. With regard to this, it is considered as adequate to set the maximum limit of the rate under discussion at $9 \%$, in order to establish if the turnover is physiological or rather expresses a scarce attention to the expectations of the interlocutors under discussion. With regard to this, the collected data highlight that only five ${ }^{7}$ companies, among the analyzed ones, feature a turnover rate below the threshold for all the considered years (see Table 8).

Table 8

Turnover Rate Below 9\%

\begin{tabular}{llll}
\hline Variaile & No. of societies, 2007 & No. of societies, 2008 & No. of societies, 2009 \\
\hline Employees turnover rate & 4 & 5 & 5 \\
\hline
\end{tabular}

The accidents on working place indicator partially expresses the safety level guaranteed by the company to its workers; with regard to this, a value to be considered as adequate in order to be socially sustainable doesn't have to be above 10. With regard to this, the gathered data show that companies with an accident frequency indicator below the threshold are three (see Table 9).

Table 9

Accidents on Working Place Frequency

\begin{tabular}{llll}
\hline Variable & No. of companies, 2007 & No. of companies, 2008 & No. of companies, 2009 \\
\hline Accindents on working place frequency indicator & 3 & 3 & 3 \\
\hline
\end{tabular}

Similarly to the above mentioned indicators, the number of training hours per year shows the inclination of the company towards the satisfaction of the sub-ordinates expectation, especially, the training ones. In order to interpret the indicator under discussion, the threshold of 20 hours per year was adopted; with regard to this, four companies exceed this threshold in all considered years (see Table 10).

Table 10

Yearly Training Hours Above 20

\begin{tabular}{llll}
\hline Variable & No. of companies, 2007 & No. of companies, 2008 & No. of companies, 2009 \\
\hline Avarage training hours per year & 4 & 4 & 4 \\
\hline
\end{tabular}

With regard to discriminating practices episodes, none of the examined companies declare its manifestation; the indicator under discussion reflects the diffusion degree of a corporate culture marked by the respect of ethical and sustainability principles.

\footnotetext{
${ }^{7}$ It has to be remembered that, as far as 2007 is concerned, the examined societies are five because A2A was founded in 2008.
} 
Finally, the presence or absence of possible sanctions against the company highlights the level of non-observance of the provisions of the law with a consequent prejudice on the community of reference. With regard to this, it is believed that the adoption of sustainable behaviours implies the absence of sanctions. From the observation of the gathered data it emerges that only four companies among the considered ones haven't been inflicted of any sanction.

From the analysis of the above explained data it emerges how few companies respected all the above mentioned indicators in 2007, 2008 and 2009; in particular, from the analytic comparison of the collected information it is evicted that the companies that contextually observe all the above mentioned conditions are only three.

The previous consideration constitutes the premise to evaluate if the assumption of corporate bodies decisions in respect of the sustainability conditions (economic, environmental and social) really simplifies the attainment of company success. With regard to this, it was appraised both the corporate value of the three companies that distinguish themselves for the application of corporate governance systems oriented towards the realization of sustainable development and of the other company situations examined (included the public utilities that don't carry out the sustainability report). In order to appraise the value dimension referable to each company, the indicators highlighted before were adopted, more precisely:

- average proceeds of sales not inferior to $€ 1,000,000,000.00$ (competitive success);

- average ebitda above $€ 200,000,000.00$ (economic success);

- inclusion in the basket of the ethical index FTSE4Good Europe (social and environmental success).

Only those companies that meet the three above mentioned conditions at the same time are considered, for the present research, as susceptible of producing value according to the meaning adopted for the present work.

With regard to the three companies that distinguish themselves for the application of corporate governance systems oriented to the respect of sustainability conditions, the observance of conditions of both economic and competitive success is noticed, while only one company also answers to the requirements of social and environmental success. It has to pointed out anyway that the condition for the verification of the socio-environmental company growth, especially the admission in the basket of the ethic index FTSE4Good Europe, sets up a condition of difficult realization considered the strictness of the checks to which the companies are exposed for this purpose. The other public utilities (four in total) even if they publish their sustainability report, don't feature, according to the indicators used, corporate governance systems fully oriented towards the sustainable development, it is fair to point out that all the companies meet the requirement of competitive and economic success, while none of them answers to the requirements for the creation of socio-environmental value. The inclination of the companies towards the value creation, at least economic and competitive, despite the incomplete correspondence to the sustainability criterions, finds a justification in the evidence that proves that the non-alignment of these indicators assumes, unless exceptions arise, a modest entity.

Finally, it was noticed instead that those public utilities that don't carry out a sustainability report (10 in total) don't meet any of the conditions requested in order to create value in medium-long term (average proceeds of sales non inferior to $€ 1,000,000,000.00$; average ebitda higher that $€ 200,000,000.00$; admission in the basket of the ethical index FTSE4Good Europe). Such empiric evidence highlights how the scarce attention to the acknowledgement of even non-economic expectations, in this case manifested by the absence of the use of a 
specific tool dedicated to the communication of socio-environmental performances, can compromise the growth of the company in the course of time. With regard to this, it is adequate to report that the selected years were interested by a strong global crisis that compromised, even if different measures, the economic performances of the enterprises taken into consideration.

\section{Conclusions}

In the last years the awareness that the corporate systems are effective only in the presence of significant potentialities of fair satisfaction of all legitimate expectations that merge in them in respect of ethical, equity and sustainable development has been affirmed. In this sense, the enlargement of the relevant success dimension is experienced and the need of a fair adaptation of economic growth, social development and environmental protection is sharpened.

In the above mentioned context, the affirmation of effective corporate governance processes sets up a critical condition for value creation in the course of time; in particular, in order to optimize the company performances, the companies are asked to apply processes of orientation of the corporate activity towards the fair adaptation of all instances issued by the different stakeholders according to the conditions of wide sustainability.

More precisely, in order that the execution of corporate governance processes feed the creation of value in time, a sharp focus on sustainable development is requested.

What was outlined before finds a confirmation in the empiric evidence above explained; from the delivered research it emerges actually how public utilities that promote behaviours in line with the sustainability conditions (social, environmental, economic and competitive) are marked out by stable growth paths.

Conversely the enterprises that assume a vision mainly addressed to the economic dimension, neglecting the other areas are generally compromised in the performance realized.

The former considerations highlight therefore the tight correlation among corporate governance processes, sustainable development and corporate value; however the enterprises are requested a bigger commitment, compared to what has been applied so far, with regard to both the processes of communication activated (especially through the arrangement of the sustainability report) and the behaviours actually executed. Until today few are the public utilities listed in the Italian Stock Exchange that carry out the sustainability report and that, in case they arrange the document under discussion, fully meet the conditions of sustainable development.

\section{References}

AA.VV. (2005). Modelli di rendicontazione etico-sociale e applicazioni pratiche. Milano: FrancoAngeli (In italian). Carnevale, C. (2005). L'informazione etico-sociale nella comunicazione d'impresa. Milano: FrancoAngeli (In italian). Carroll, A. B. (1993). Business and society: Ethics and stakeholder management. Cincinnati: South Western.

De George, R. T. (1993). Competing with integrity in international business. Oxford: Oxford University Press.

De George, R. T. (1999). Business ethics. Upper Saddle River: Prentice Hall.

Donaldson, T. (1982). Corporation and morality. Englewood Cliffs: Prentice Hall.

Dowell, G., Hart, S., Yeung, B. (2000). Do corporate environmental standards create or destroy market value? Management Science, 46(8), 1059-1074.

Elkington, J. (1997). Cannibals with forks. The triple bottom line of 21th century business. Oxford: Capstone.

Estes, R. (1976). Corporate social accounting. New York: Whiley \& Sons Inc..

Freeman, R. E. (1984). Strategic management: A stakeholder approach. Boston: Pitman.

Fukuyama, F. (1995). Trust: The social virtues and the creation of prosperity. New York: The Free Press. 
Gray, R., Bebbington, J., \& Walters, D. (1993). Accounting for the environment. London: Paul Chapman.

Gray, R., Owen, D., \& Mauders, K. (1987). Corporate social reporting, accounting and accountability. London: Prentice Hall International.

Jacobs, M. (1997). The environment as stakeholder. Business Strategy Review, 6(2), 25-28.

Jacoby, N. H. (1973). Corporate power and social responsibility. New York: Mac Millan.

Lantos, G. P. (2001). The boundaries of strategic corporate social responsibility. Journal of Consumer Marketing, 18(7), 595-630.

Mathews, M. R. (1993). Socially responsible accounting. London: Chapman Hall.

Mc Williams, A., \& Siegel, D. (2000). Corporate social responsibility and financial performance: Correlation or misspecification? Strategic Management Journal, 21, 603-609.

Mio, C. (2005). Corporate social responsibility e sistema di controllo: verso l'integrazione. Milano: FrancoAngeli (In italian).

Molteni, M. (2006). Responsabilità sociale e performance d'impresa. Milano: Vita e Pensiero (In italian).

Newgren, K. E., Rasher, A. A., LaRoe, M. E., \& Szabo, M. R. (1985). Environmental assesment and corporate performance: A longitudinal analysis using a market-determined performance measure. Research in Corporate Social Performance and Policy, 7, 153-164.

Paine, L. S. (2003). Value shift: Why companies must merge social and financial imperative to achieve superior performance. New York: McGraw-Hill.

Porter, M. E., \& Van Der Linde, C. (1995). Towards a new conception of the environment-competitiveness relationship. Journal of Economic Perspectives, 9(4), 119-150.

Riahi Belkaoui, A. (1996). Performance results in value added reporting. Westport: Quorum.

Roome, N. (1992). Sustainability strategies for industry. The future of corporate strategy. Washington: Island.

Salvioni, D. M. (2003). Corporate governance and global responsibility. Symphonya. Emerging Issues in Management, 1, 47-60.

Salvioni, D. M. (2005). Corporate governance, management controland global competition. Symphonya. Emerging Issues in Management, 1.

Salvioni, D. M. (2009). Corporate governance, controllo e trasparenza. Milano: FrancoAngeli (In italian).

Simerly, R. L. (1999). Measuring corporate social performance: An assessment of techniques. International Journal of Management, 16(2), 253-257.

Stevens, W. P. (1984). market reaction to corporate environmental performance. Advances in Accounting, 1, 41-61.

Tencati, A. (2002). Sostenibilità, impresa e performance. Milano: Egea (In italian).

Testa, M. (2007). La responsabilità sociale d'impresa. Torino: Giappichelli (In italian).

Valentini, S. (2004). Responsabilità sociale d'impresa e globalizzazione. Milano: FrancoAngeli (In italian).

Waddock, S. A., Graves, S. B. (1997). The corporate social performance-Financial performance link. Strategic Management Journal, 18(4), 303-319.

Waddock, S. A., \& Graves, S. B. (1999). Assesing the link between corporate governance and social-financial performance. In Proceedings of the International Association for Business and Society Tenth, 221-226.

Walden, W. D., \& Schwartz, B. N. (1997). Environmental disclosures and public policy pressure. Journal of Accounting and Public Policy, 16(2), 124-154.

Welford, R. (2000). Corporate environmental management. Towards sustainable development. London: Earthscan Publications.

Welford, R., \& Gouldson, A. (1993). Environmental management and business strategy. London: Pitman. 